\title{
EVOLUÇÃO DA EFICIÊNCIA DE ESCALA DE OPERADORES LOGÍSTICOS FRIGORIFICADOS NO BRASIL
}

\author{
Carlos Ernani Fries \\ Universidade Federal de Santa Catarina \\ carlos.fries@ufsc.br \\ Ismael Peruzzo Zamoner \\ Catalitica Consultoria de Gestão \\ ipzamoner@gmail.com \\ Fernanda Christmann \\ Universidade Federal de Santa Catarina \\ fe.christmann@grad.ufsc.br
}

\begin{abstract}
Resumo
Este trabalho apresenta uma análise da evolução da eficiência de escala de operadores logísticos frigorificados que operaram no mercado brasileiro no período de 2007 a 2010. O estudo faz uso de Análise Envoltória de Dados e procedimentos estatísticos fundamentados na análise de componentes principais para seleção das variáveis input e output utilizadas na análise. Para a elaboração do estudo foram empregados dados secundários extraídos de uma publicação especializada da área de Logística. Os resultados mostram que o setor apresentou taxa de crescimento elevado e que as empresas acompanharam esta tendência. Retornos decrescentes de escala não foram observados na amostra considerada, o que sugere que o mercado apresentava potenciais de crescimento de escala ainda inexplorados pelos operadores logísticos frigorificados. O trabalho ainda apresenta análises da evolução dos escores de eficiências com eventos anuais relacionados à alteração do porte de três empresas emblemáticas que operaram no setor.

Palavras-Chaves: Eficiência de Escala, Análise de Envelopamento de Dados; Operadores Logísticos Frigorificados.
\end{abstract}

\begin{abstract}
This paper presents an analysis of the evolution of temperature-controlled logistics operators scale efficiency that operated from 2007 to 2010 in the Brazilian market. The study uses data envelopment analysis and statistical techniques based on principal component analysis for the selection of input variables and output used in the analysis. To develop this study secondary data taken from a specialized publication of the Logistics area were used. The results show that the sector had high growth rate and that companies size followed this trend. Decreasing returns to scale were not observed in this sample which suggests that the market have had potential scale growth untapped by the logistics service firms that operated in cold supply chains in the years considered in this study. The work also presents an analysis of the evolution of scale efficiency scores with annual events related to change the size of three flagship companies.

Keywords: $\quad$ Scale Efficiency; Data Envelopment Analysis; TemperatureControlled Logistics Service Providers.
\end{abstract}




\section{INTRODUÇÃO}

Operadores logísticos frigorificados são empresas que armazenam e/ou transportam bens perecíveis, os quais são suscetíveis à deterioração devido a falhas na cadeia de refrigeração. $\mathrm{O}$ objetivo destas empresas é reduzir as perdas, atendendo prazos estabelecidos e mantendo controlada a variação da temperatura dos bens perecíveis.

Operadores logísticos têm aumentado sua participação na indústria de serviços logísticos devido à crescente terceirização destes serviços nas últimas duas décadas. Empresas responsáveis por esse tipo de terceirização oferecem normalmente pacotes de serviços que incluem não apenas o transporte em si, mas também informações associadas ao serviço de transporte. Para Sink e Langley (1997), uma das razões do crescimento das atividades terceirizadas é decorrente do incremento da competitividade observada no mercado. Isto forçou empresas a direcionar seus esforços para suas atividades principais, que são críticas para sua sobrevivência. Desta forma, as atividades logísticas acabam tendo maior grau de terceirização, por não ser parte do negócio central da empresa. Com isso, cria-se a necessidade de contratar empresas operadoras logísticas, que muitas vezes ajudam na expansão do alcance dos produtos, junto à melhoria na qualidade dos serviços.

O operador logístico frigorificado se diferencia do operador logístico comum por ter seu foco na "cadeia do frio". Segundo o órgão da Vigilância Sanitária do Brasil, a cadeia do frio consiste em "resfriar o produto desde a sua produção e mantê-lo frio ao longo de toda a sequência até o consumo final". A Figura 1 mostra um esquema das atividades desta cadeia do frio.

Figura 1: Esquema das atividades da cadeia do frio.

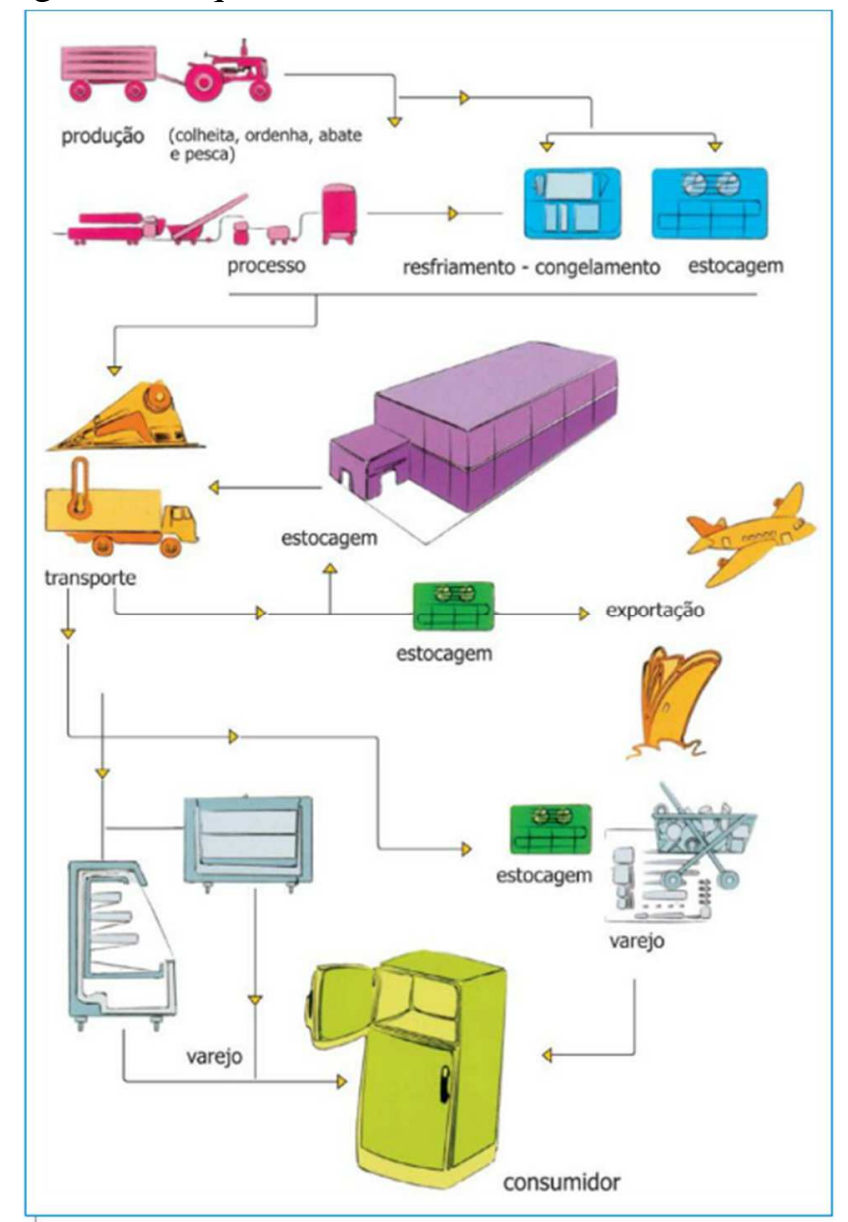

Fonte: Camargo e Silveira (2010) 
Segundo levantamento da Associação Brasileira da Indústria de Armazenagem Frigorificada (ABIAF), o crescimento do mercado de frigorificados no ano de 2010 foi acentuado. Do ano de 1989 a 2010, a área pública frigorificada - área disponível para qualquer embarcador interessado - teve um salto de 1,8 milhão de $\mathrm{m}^{3}$ para 5,25 milhões de $\mathrm{m}^{3}$ (MARINO, 2010). A exigência crescente deste mercado cria uma tendência de aperfeiçoamento na inteligência nos serviços, juntamente ao aumento da eficiência de seus processos de transformação de insumos em serviços.

Este trabalho visa avaliar a eficiência de escala de operadores logísticos frigorificados no Brasil no período de 2007 a 2010, traçando a evolução deste mercado que cresceu a taxas elevadas neste período.

\section{AVALIAÇÃO DE DESEMPENHO E ANÁLISE DE ENVELOPAMENTO DE DADOS (DATA ENVELOPMENT ANALYSIS - DEA)}

A avaliação periódica do desempenho relativo de uma organização pode auxiliar na caracterização e controle de seu desempenho comparativo no setor em que atua. Classicamente, essa avaliação é definida pelo lucro de uma organização, o qual quantifica seu desempenho utilizando-se de uma base única, a monetária. Em organizações de capital fechado, resultados financeiros não são públicos, fazendo com que outras formas de mensuração de desempenho sejam utilizadas. Estas mensurações, realizadas em organizações de um mesmo setor, permitem identificar aquelas empresas que operam utilizando as melhores práticas, podendo servir de referência para outras organizações que procuram melhorar sua produtividade. Modelos de avaliação permitem estabelecer rankings de desempenho operacional que, aliados ao conhecimento de suas características, permitem construir hipóteses a respeito da relação destas características com as medidas de desempenho apuradas.

A eficiência técnica de uma empresa é definida pela relação entre sua produtividade e a produtividade máxima do processo. Segundo Ray e Chen (2009), "usando uma amostra atual de dados de input-output observados, determinam-se referências de mercado, com as quais uma empresa pode ser comparada para mensurar sua eficiência". O objetivo é mensurar a eficiência relativa dos produtores e observar as melhores práticas dentro deste universo. Para cada produtor, também conhecido como unidade de decisão (Decision Making Unit DMU), são atribuídos pesos aos inputs empregados no processo de transformação de insumos em produtos, ou outputs.

Dois são os principais modelos que definem análise por envoltória de dados: os modelos CCR (CHARNES, COOPER e RHODES, 1978) e BCC (BANKER, CHARNES e COOPER, 1984). O modelo CCR assume que retornos de escala das atividades realizadas pela empresa são constantes. Conforme Cooper et al. (2007), o modelo CCR pode ser representado por um problema de programação linear, para uma DMU $o$ específica:

$\max _{\mathrm{u}, \mathrm{v}} \theta=u_{1} y_{1 o}+u_{2} y_{2 o}+\ldots+u_{s} y_{s o}$

sujeito a

$$
\begin{aligned}
& v_{1} x_{1 o}+\ldots+v_{m} x_{m o}=1 \\
& u_{1} y_{1 j}+\ldots+u_{s} y_{s j} \leq v_{1} x_{1 j}+\ldots+v_{m} x_{m j} \\
& v_{1}, v_{2}, \ldots, v_{m} \geq 0 \\
& u_{1}, u_{2}, \ldots, u_{s} \geq 0
\end{aligned}
$$

$$
\operatorname{com} j=1, \ldots, n
$$

onde para uma dada DMU $j$ os inputs são dados por $\left(x_{1 j}, x_{2 j}, \ldots, x_{m j}\right)$ e os outputs por $\left(y_{1 j}, y_{2 j}\right.$, $\left.\ldots, y_{s j}\right)$. Ademais, pesos para inputs e outputs são dados respectivamente pelas variáveis $\left(v_{i}\right)$, com $i=1, \ldots, m$ e $\left(u_{r}\right), \operatorname{com} r=1, \ldots, s$. Define-se que para uma DMU ser eficiente, $\theta^{*}=1$, onde haja um par ótimo $\left(v^{*}, u^{*}\right), \operatorname{com} v^{*}>0$ e $u^{*}>0$. Qualquer valor de $\theta^{*}<1$ ou uma situação 
onde $\theta^{*}=1$, mas $v^{*}=0$ ou $u^{*}=0$ representam uma DMU ineficiente. Para o modelo CCR foram propostas várias extensões sendo que uma delas, o chamado modelo BCC, incorpora retornos variáveis de escala na relação input-output. Segundo Cooper et al. (2007), o modelo BCC de programação linear para uma DMU $o(\operatorname{com} o=1, \ldots, n)$, na forma vetorial, é dado por: $\min _{\Theta b, \lambda} \theta_{B}$

sujeito a

$$
\begin{aligned}
& \theta_{B} x_{o}-X \lambda \geq 0 \\
& Y \lambda \geq y_{o} \\
& e \lambda=1 \\
& \lambda \geq 0,
\end{aligned}
$$

onde os valores de $(X, Y)$ são os valores de inputs e outputs de acordo com a base de dados, $\lambda$ é um vetor coluna com todos os valores não-negativos e $e$ é um vetor linha com todos os elementos iguais a 1 . A variável $\theta_{B}$ é um escalar real, com valores entre 0 e 1 , sendo que ao atingir 1, a DMU é caracterizada como eficiente. A relação das medidas de eficiência derivadas dos modelos CCR e BCC é definida por Cooper et al. (2007) como eficiência de escala. Ou seja, caso $\theta^{*}{ }_{C C R}$ e $\theta^{*}{ }_{B C C}$ representem valores obtidos por uma DMU qualquer, a eficiência de escala é definida por $\theta_{C C R}^{*} / \theta_{B C C}^{*}$.

\section{METODOLOGIA}

A metodologia para avaliação de eficiência de operadores logísticos frigorificados consistiu de uma pesquisa do tipo conclusivo-explicativa, pois verifica relações de causa e efeito (MATTAR, 1994) do emprego de insumos em produtos e a eficiência com que este processo tem efeito.

Para o desenvolvimento do trabalho, a série histórica de dados das empresas foi obtida através de consulta à edição do mês de julho da Revista Tecnologística, entre os anos de 2007 e 2010. As informações foram coletadas pela revista diretamente com as empresas, através de um questionário que foi respondido por email ou telefone. A revista apresenta dados relacionados com variáveis do volume de produtos gerenciados por ano, área de armazenagem, frota de transporte, serviços oferecidos, tecnologias empregadas, dentre outros.

A seleção de variáveis input e output que caracterizam o processo de transformação do setor de serviços logísticos frigorificados é uma etapa crítica da metodologia. A análise de correlação entre variáveis teve aplicação dificultada devido ao número relativamente reduzido de casos para sua aplicação. Alternativamente, fez-se uso de Análise de Componentes Principais (ACP), a qual permite identificar componentes principais através de combinações lineares das variáveis originais, eventualmente reduzindo, assim, a dimensionalidade da base de dados. Definiu-se arbitrariamente que resultados significativos deveriam representar, no mínimo, $80 \%$ do poder de explicação da amostra nas componentes principais identificadas.

Finalmente, na última etapa da análise, foram aplicados os modelos CCR e BCC da abordagem DEA para determinar os escores de eficiência relativa dos operadores logísticos frigorificados, considerando retornos constantes e variáveis de escala, respectivamente. Nesta etapa foram identificados aqueles prestadores de serviços logísticos que se encontram na fronteira de eficiência e aqueles ineficientes, ou seja, que se encontram abaixo da mesma.

\section{RESULTADOS}

Os resultados incluem a seleção das variáveis input-output via Análise de Componentes Principais, a determinação dos escores de eficiência e uma projeção dos escores de eficiência de escala para as empresas consideradas nos anos da pesquisa. 
Em virtude da pouca representatividade individual dos diferentes tipos de veículos (Carga Seca, Baú, Slider, Refrigerada e Utilitários), optou-se por agregar todas as quantidades destes numa única variável denominada "Frota Própria Total". O Quadro 1 apresenta a lista de variáveis utilizadas na ACP. Desta lista, fez-se a seleção daquelas variáveis com maior poder de explicação da variância observada na amostra. Os resultados da seleção de variáveis conduziram a um conjunto de variáveis com alto poder de explicação da variação observada na amostra de dados de 2007 a 2010. Do resultado, foi utilizada a combinação de cinco componentes principais, com $87 \%$ de poder de explicação da variância observada na amostra de dados. A importância relativa de cada variável para a formação das cinco componentes é dada pelo gráfico da Figura 2.

Quadro 1: Variáveis empregadas na Análise de Componentes Principais (ACP).

\begin{tabular}{|ll|}
\hline Variável & Unidade \\
\hline Tempo de Mercado & anos \\
Número de Funcionários & funcionários \\
Receita Bruta Anual & milhões de reais \\
Frota Terceirizada & Sim ou Não \\
Número de Clientes & clientes \\
Área de Armazenamento - Alfandegada & $\mathrm{m}^{3}$ \\
Área de Armazenamento - Pátio & $\mathrm{m}^{3}$ \\
Número de tomadas & tomadas \\
Número Total de Armazéns - Próprios & armazéns \\
Número Total de Armazéns - De Clientes & armazéns \\
Frota Própria Total & veiculos \\
Volume Total de Produtos Gerenciados - & itens/ano \\
Ém unidades & $\mathrm{t} /$ ano \\
Volume Total de Produtos Gerenciados - & $\mathrm{m}^{2}$ \\
Ém peso & $\mathrm{m}^{3}$ \\
Área armazenagem - Congelada & $\mathrm{m}^{2}$ \\
Área armazenagem - Congelada & $\mathrm{m}^{3}$ \\
Área armazenagem - Resfriada & $\mathrm{m}^{2}$ \\
Área armazenagem - Resfriada & $\mathrm{m}^{3}$ \\
Área armazenagem - Climatizada & $\mathrm{m}^{2}$ \\
Área armazenagem - Climatizada & $\mathrm{m}^{3}$ \\
Área armazenagem - Seca & 20 área armazenagem - Seca \\
\hline
\end{tabular}

Fonte: Zamoner, 2012.

Foram selecionadas as quatro variáveis que compõem as cinco componentes principais: "Número Total de Armazéns - de Clientes"; "Número Total de Armazéns Próprios"; "Número de Tomadas" e "Volume de Produtos Gerenciados - em Peso (t/ano)". Das quatro variáveis selecionadas, tem-se que as três primeiras representam inputs naturais do processo de transformação, enquanto que a quarta variável representa um output representativo deste processo. 
Figura 2: Importância relativa das variáveis nas componentes da análise ACP.

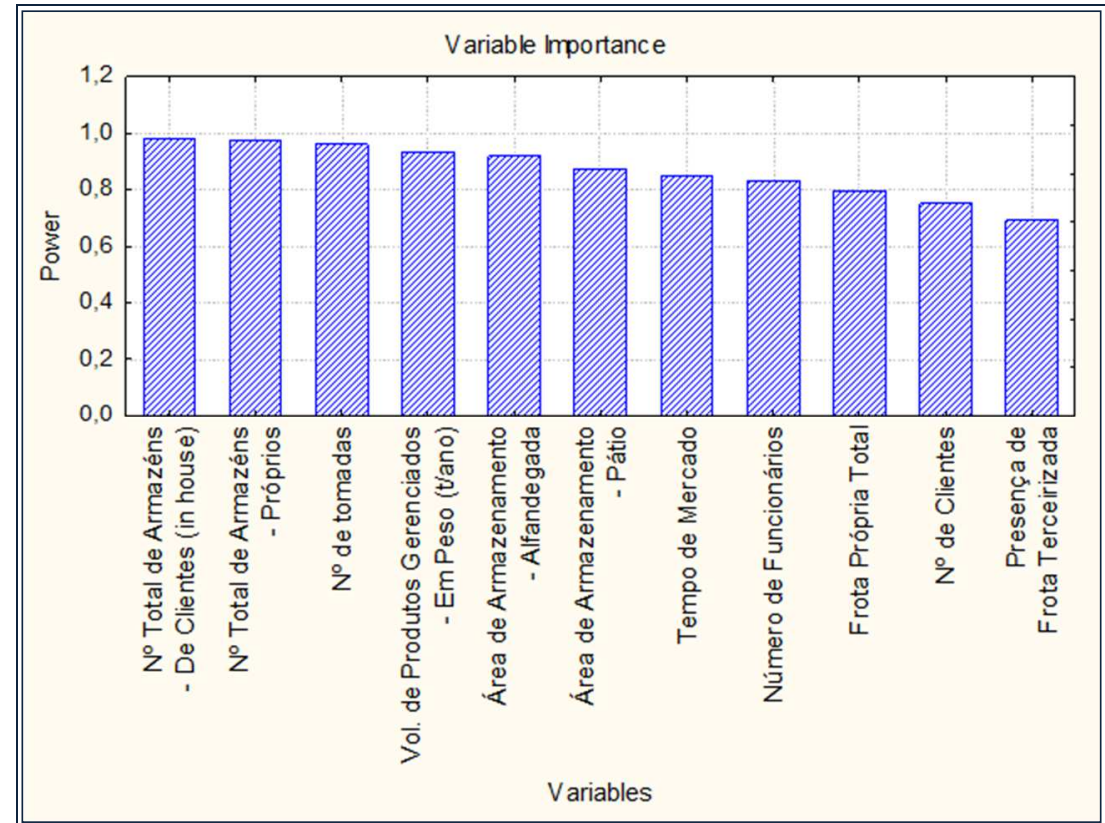

A aplicação dos modelos DEA de retorno constante e variável de escala foi executada para cada ano da amostra, ou seja, de 2007 a 2010. A determinação das eficiências de escala se deu pela simples relação dos escores de eficiência obtidos com os modelos CCR e BCC. Os resultados obtidos para os anos de 2007 a 2010 compõem a Tabela 1. 
Tabela 1 - Escores de eficiência para os anos de 2007 a 2010.

\begin{tabular}{|c|c|c|c|}
\hline Unidade de avaliação (DMU) & $\begin{array}{l}\text { Modelo } \\
\text { BCC }\end{array}$ & $\begin{array}{l}\text { Modelo } \\
\text { CCR }\end{array}$ & $\begin{array}{l}\text { Eficiência } \\
\text { de escala }\end{array}$ \\
\hline $\begin{array}{l}\text { AGV Logistica - Armazéns } \\
\text { Gerais Vinhedo }\end{array}$ & 0,17 & 0,14 & 0,84 \\
\hline CAP - Logistica Frigorificada & 1,00 & 0,51 & 0,51 \\
\hline Cefri & 1,00 & 1,00 & 1,00 \\
\hline Comfrio & 0,28 & 0,28 & 0,98 \\
\hline Coopercarga & 0,18 & 0,14 & 0,76 \\
\hline FBD-Luft & 0,50 & 0,14 & 0,29 \\
\hline Fibra Logistica & 1,00 & 0,95 & 0,95 \\
\hline Frigoserv & 1,00 & 0,43 & 0,43 \\
\hline Friozem & 1,00 & 0,73 & 0,73 \\
\hline Libraport Campinas & 0,20 & 0,01 & 0,06 \\
\hline Localfrio & 0,17 & 0,08 & 0,46 \\
\hline Log Frio Logistica & 0,50 & 0,09 & 0,19 \\
\hline Logimasters \& Dachser & 1,00 & 1,00 & 1,00 \\
\hline Martin-Brower & 0,33 & 0,30 & 0,90 \\
\hline MBB Comércio e Serviços & 1,00 & 0,06 & 0,06 \\
\hline Multilog & 0,17 & 0,09 & 0,55 \\
\hline Perfrio Armazéns Gerais & 1,00 & 0,11 & 0,11 \\
\hline Rodoviário Schio & 0,24 & 0,06 & 0,26 \\
\hline Santa Rita Logistic & 0,34 & 0,31 & 0,90 \\
\hline Standard & 1,00 & 1,00 & 1,00 \\
\hline Tuiuti Indústria e Comércio & 1,00 & 1,00 & 1,00 \\
\hline
\end{tabular}

\begin{tabular}{llll}
\hline \multicolumn{4}{c}{2008} \\
Unidade de avaliação (DMU) & $\begin{array}{l}\text { Modelo } \\
\text { BCC }\end{array}$ & $\begin{array}{l}\text { Modelo } \\
\text { CCR }\end{array}$ & $\begin{array}{l}\text { Eficiência } \\
\text { de escala }\end{array}$ \\
\hline $\begin{array}{l}\text { AGV Logistica - Armazéns } \\
\text { Gerais Vinhedo }\end{array}$ & 0,50 & 0,25 & 0,50 \\
Brasfrigo & 1,00 & 0,67 & 0,67 \\
CAP - Logistica Frigorificada & 1,00 & 0,47 & 0,47 \\
Cefri & 1,00 & 1,00 & 1,00 \\
\hline Cefrinor & 1,00 & 0,80 & 0,80 \\
\hline Comfrio & 0,46 & 0,32 & 0,68 \\
FBD-Luft & 0,75 & 0,33 & 0,44 \\
\hline Fibra Logistica & 1,00 & 0,30 & 0,30 \\
Frigorificos Catei & 0,58 & 0,07 & 0,13 \\
Friozem & 1,00 & 0,84 & 0,84 \\
ID Logistics & 1,00 & 1,00 & 1,00 \\
\hline Localfrio & 0,17 & 0,07 & 0,39 \\
Log Frio Logistica & 0,40 & 0,08 & 0,20 \\
\hline Logimasters \& Dachser & 0,50 & 0,43 & 0,86 \\
\hline Martin-Brower & 1,00 & 1,00 & 1,00 \\
\hline Multilog & 0,22 & 0,08 & 0,35 \\
\hline Perfrio Armazéns Gerais & 0,24 & 0,07 & 0,31 \\
\hline Refrio Armazéns Frigorificos & 0,56 & 0,52 & 0,93 \\
Rodoviário Schio & 0,22 & 0,12 & 0,53 \\
\hline Standard & 1,00 & 1,00 & 1,00 \\
\hline Sun Plant & 1,00 & 0,59 & 0,59 \\
\hline
\end{tabular}

2009

\begin{tabular}{|c|c|c|c|}
\hline Unidade de avaliação (DMU) & $\begin{array}{l}\text { Modelo } \\
\text { BCC }\end{array}$ & $\begin{array}{l}\text { Modelo } \\
\text { CCR }\end{array}$ & $\begin{array}{l}\text { Eficiência } \\
\text { de escala }\end{array}$ \\
\hline $\begin{array}{l}\text { AGV Logistica - Armazéns } \\
\text { Gerais Vinhedo }\end{array}$ & 1,00 & 0,32 & 0,32 \\
\hline Andrade Cavaletti Logistica & 0,50 & 0,08 & 0,16 \\
\hline Augsue Armazéns & 1,00 & 1,00 & 1,00 \\
\hline CAP - Logistica Frigorificada & 0,61 & 0,54 & 0,89 \\
\hline Cefri & 1,00 & 1,00 & 1,00 \\
\hline Comfrio & 0,50 & 0,41 & 0,83 \\
\hline FBD-Luft & 1,00 & 0,22 & 0,22 \\
\hline Fibra Logística & 1,00 & 0,83 & 0,83 \\
\hline Frigorificos Catei & 0,58 & 0,05 & 0,08 \\
\hline Friozem & 0,20 & 0,04 & 0,21 \\
\hline Localfrio & 0,17 & 0,06 & 0,34 \\
\hline Log Frio Logistica & 0,26 & 0,05 & 0,20 \\
\hline Logimasters \& Dachser & 1,00 & 0,19 & 0,19 \\
\hline Martin-Brower & 1,00 & 0,98 & 0,98 \\
\hline $\begin{array}{l}\text { Martini Meat Armazéns } \\
\text { Gerais }\end{array}$ & 0,55 & 0,55 & 1,00 \\
\hline Perfrio Armazéns Gerais & 0,48 & 0,09 & 0,19 \\
\hline Rodoviário Schio & 0,14 & 0,10 & 0,72 \\
\hline Satel Armazéns Gerais & 1,00 & 0,26 & 0,26 \\
\hline Standard & 1,00 & 1,00 & 1,00 \\
\hline Super Frio & 0,88 & 0,03 & 0,03 \\
\hline Tuiuti Indústria e Comércio & 1,00 & 0,32 & 0,32 \\
\hline
\end{tabular}

2010

\begin{tabular}{llll}
\hline Unidade de avaliação (DMU) & $\begin{array}{l}\text { Modelo } \\
\text { BCC }\end{array}$ & $\begin{array}{l}\text { Modelo } \\
\text { CCR }\end{array}$ & $\begin{array}{l}\text { Eficiência } \\
\text { de escala }\end{array}$ \\
\hline $\begin{array}{l}\text { AGV Logistica - Armazéns } \\
\text { Gerais Vinhedo }\end{array}$ & 0,40 & 0,29 & 0,72 \\
\hline Cefri & 1,00 & 0,36 & 0,36 \\
\hline Cefrinor & 1,00 & 0,35 & 0,35 \\
\hline Comfrio Soluções Logisticas & 0,21 & 0,00 & 0,00 \\
\hline Frigorifi cos Catei & 1,00 & 0,05 & 0,05 \\
\hline Friozem Logistica & 0,61 & 0,55 & 0,91 \\
\hline Interporti & 1,00 & 0,95 & 0,95 \\
\hline Localfrio & 0,17 & 0,03 & 0,17 \\
\hline Log Frio Logistica & 0,71 & 0,16 & 0,22 \\
\hline Logimasters & 1,00 & 0,07 & 0,07 \\
\hline Luft Food Service & 1,00 & 1,00 & 1,00 \\
\hline Martin-Brower & 1,00 & 0,76 & 0,76 \\
\hline Perfrio Armazéns Gerais & 0,43 & 0,06 & 0,14 \\
\hline Refrio Armazéns Gerais & 1,00 & 1,00 & 1,00 \\
\hline Rodoviário Schio & 1,00 & 1,00 & 1,00 \\
\hline Safrio & 0,90 & 0,64 & 0,71 \\
\hline Standard & 0,50 & 0,44 & 0,89 \\
\hline Stock Tech & 0,52 & 0,47 & 0,91 \\
\hline Sun Plant & 1,00 & 0,43 & 0,43 \\
\hline
\end{tabular}

Os escores da eficiência de escala foram relacionados, ano a ano, com os respectivos valores de outputs de cada empresa de forma a permitir a análise comparativa entre eficiência de escala e magnitude do "Volume Total de Produtos Gerenciados - em Peso", medido em toneladas gerenciadas em cada um dos anos. Os gráficos desta relação estão apresentados nas 
Figuras 3, 4, 5 e 6, para os anos 2007, 2008, 2009 e 2010, respectivamente. Uma avaliação direta destes gráficos permite deduzir que os resultados mostram o comportamento esperado para a relação eficiência de escala e "Volume Total de Produtos Gerenciados - em Peso". Isto é, empresas com pequenos volumes gerenciados anualmente tendem a apresentar maiores ineficiências de escala. Isto seria um indicativo que estas empresas operam abaixo da escala ideal para o mercado observado no respectivo ano e deveriam, portanto, ampliar suas atividades porque o mercado de operadores logísticos frigorificados tem apresentado altas taxas de crescimento nos anos considerados na pesquisa (2007-2010). A curva ajustada de segundo grau indica que para o ano de 2007 , o volume gerenciado com máxima eficiência de escala esperada seria de aproximadamente 800 mil toneladas.

Figura 3: Relação entre eficiência de escala e "Volume Total de Produtos Gerenciados - em Peso" para o ano de 2007.

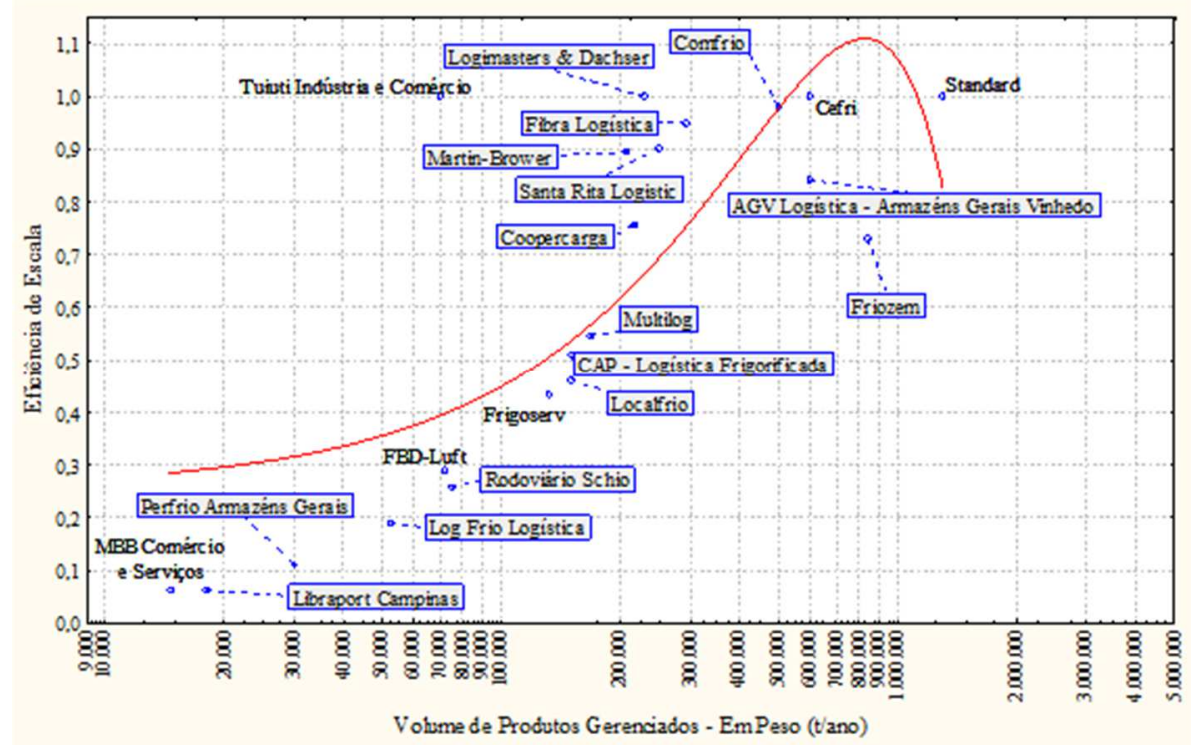

Para o ano de 2008 (Figura 4), o volume gerenciado ajustado que conduz à máxima eficiência de escala é de pouco mais de 1.000 mil toneladas. Este deslocamento do nível de operação ideal do ano de 2007 para 2008 deu-se devido ao crescimento observado na economia no Brasil no ano de 2008 (5.2\% segundo dados do IBGE) e ao crescimento das atividades relacionadas à movimentação de cargas refrigeradas. 
Figura 4: Relação entre eficiência de escala e "Volume Total de Produtos Gerenciados - Em peso" para o ano de 2008.

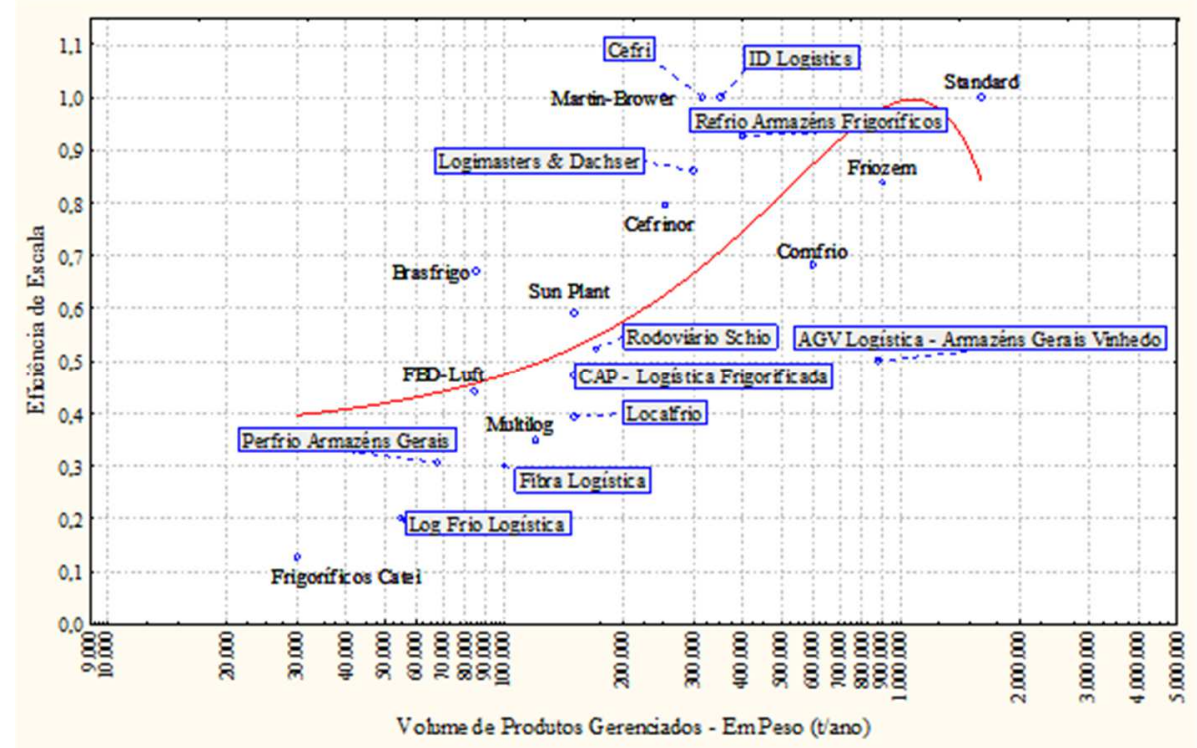

A curva ajustada da relação de eficiência com os volumes gerenciados para o ano de 2009 mostra um leve deslocamento para a direita do ponto de escala ideal de operação. A taxa de crescimento foi inferior ao registrado no ano anterior. Este fato foi possivelmente afetado pelo baixo crescimento auferido pela economia brasileira naquele ano $(0.3 \%$, segundo dados do IBGE).

Figura 5: Relação entre eficiência de escala e "Volume Total de Produtos Gerenciados - Em peso" para o ano de 2009.

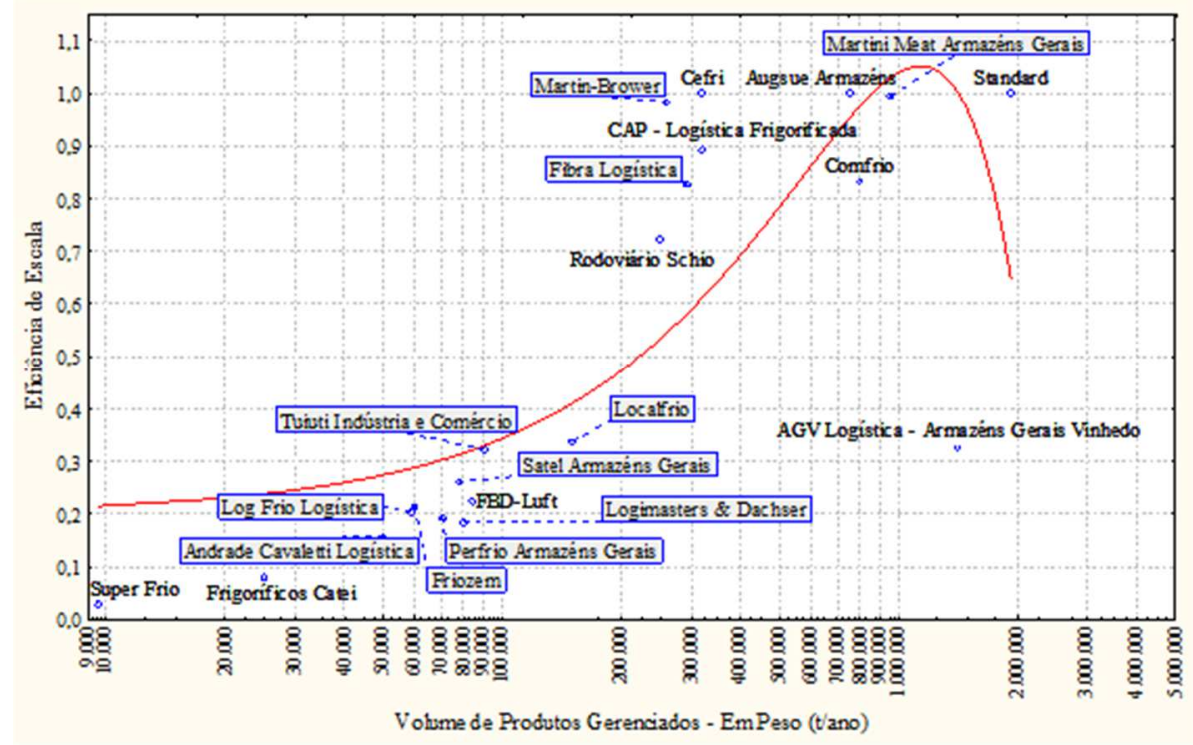

Os resultados obtidos para o ano de 2010 mostram um deslocamento vigoroso para a direita da escala ótima de operação dos operadores logísticos que operam no mercado brasileiro. O nível de operação ajustado que configura escala ideal de operação situa-se em torno de 2.500 mil toneladas movimentadas o que perfaz incremento de mais de $100 \%$ na escala ótima, em relação ao ano anterior. Muito provavelmente este impacto decorre do forte crescimento da economia no ano de 2010 (7.5\% segundo dados do IBGE), mas também pela já mencionada necessidade ampliar o nível de atividade, observado na análise feita para os anos de 2007 e 2008. 
Figura 6: Relação entre eficiência de escala e "Volume Total de Produtos Gerenciados - Em peso" para o ano de 2010.

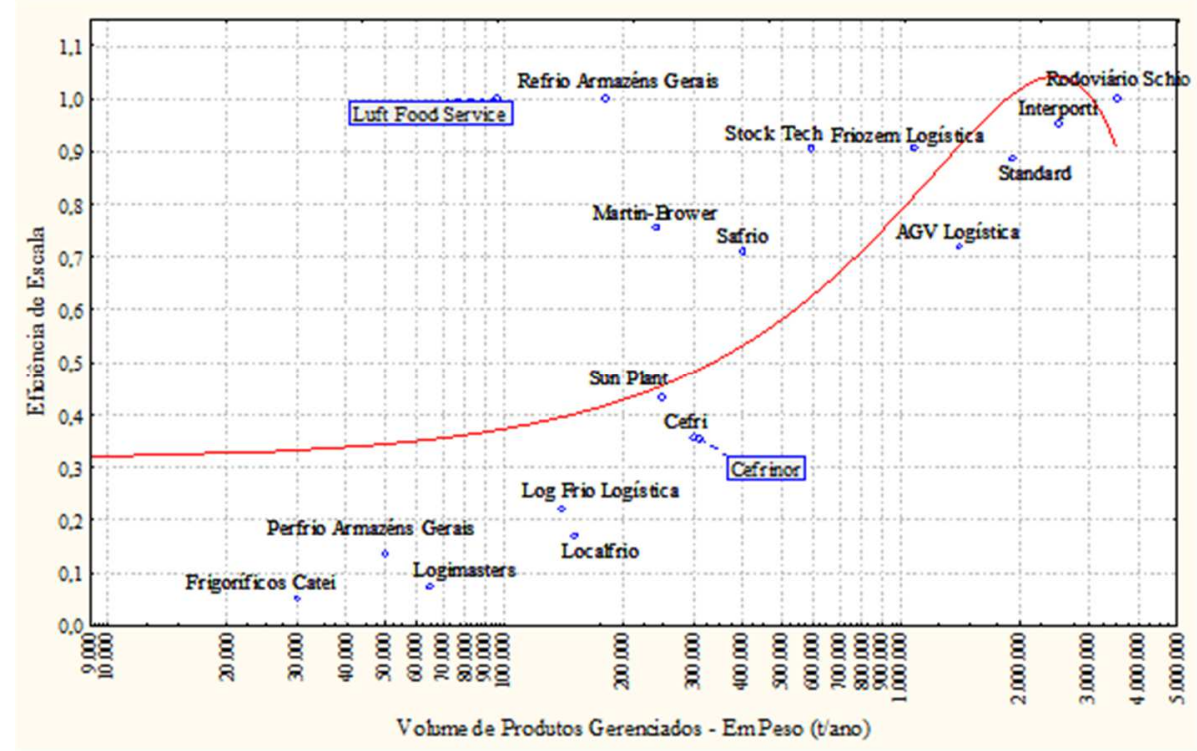

Os resultados obtidos permitem traçar a evolução de cada uma das DMUs incluídas na análise, considerando dados secundários disponíveis na internet sobre aquisições, expansões ou fusões observadas ao longo tempo no setor de operadores logísticos refrigerados.

As empresas avaliadas individualmente são: 1) AGV Logística, que teve um grande aumento de volume total em peso transportado; 2) Standard Logística, uma operadora que manteve o papel de benchmark no setor, com elevados volumes movimentados; e 3) MartinBrower, que manteve praticamente constantes seus volumes e eficiência de escala no decorrer do período, sem acompanhar a tendência de crescimento do mercado.

A empresa $A G V$ Logística apresentou desempenho na sua eficiência de escala de acordo com a Tabela 5, para os anos 2007 a 2010.

Tabela 5 - Desempenho da empresa AGV Logística para os anos de 2007 a 2010

\begin{tabular}{cccc}
\hline Ano & Empresa & $\begin{array}{c}\text { Eficiência de } \\
\text { escala }\end{array}$ & $\begin{array}{c}\text { Volume Total de Produtos } \\
\text { Gerenciados - Em Peso } \\
\text { (ton/ano) }\end{array}$ \\
\hline 2007 & AGV Logística & 0,84 & 600.000 \\
2008 & AGV Logística & 0,50 & 880.000 \\
2009 & AGV Logística & 0,32 & 1.400 .000 \\
2010 & AGV Logística & 0,72 & 1.400 .000 \\
\hline
\end{tabular}

A $A G V$ Logística realiza o atendimento de toda cadeia logística dos seus clientes. Ela disponibiliza serviços de armazenagem, movimentação e controle, transporte e distribuição, montagem de kits promocionais e logística promocional, rotulagem e etiquetagem de produtos, compra de insumos e assessoria logística, entre outros. Os resultados mostram a eficiência de escala da empresa em declínio, apesar do seu crescimento em porte, com uma recuperação nos valores de eficiência do último ano. De uma análise dos registros históricos relacionados com a empresa ocorridos entre 2005 a 2009, cabe destacar:

- 2005 - Empresa com crescimento nos anos anteriores de 45\% (2003-2004), fechou o ano com uma evolução de $35,7 \%$ com relação ao ano anterior e faturamento de R $\$ 70$ milhões. 
Seu carro chefe no ano e em anos anteriores foi o transporte de vacinas e medicamentos destinados à saúde animal, com 374 milhões de doses em 2004 (INTELOG, 2005);

- 2006 - Empresa inicia a construção de seu mais moderno centro de distribuição, inaugurado em 2007;

- 2007 - Inaugurado em dezembro, o centro de distribuição possui uma área de 58 mil m² de área construída, com 62 mil posições-pallet distribuídas em áreas de armazenagem secas, climatizadas, refrigeradas, de produtos inflamáveis e aerossóis. Para expedição e recepção de produtos foram construídas 94 docas para movimentações. Houve expansão para o mercado de transporte de cosméticos, saúde humana e nutrição animal. Empresa encerra o ano com faturamento de $\mathrm{R} \$ 98$ milhões, com crescimento de $25 \%$ sobre o ano anterior (REVISTA TECNOLOGÍSTICA, 2008);

- 2008 - AGV Logística compra as empresas Delta Serviços Logísticos e E-Service, de logística promocional. A empresa expande o leque de serviços oferecidos e conquista clientes como Nivea, Biolab, BASF, VisaNET e Nokia. Neste ano, a empresa inaugurou três novas filiais nas cidades de Jundiaí, Recife e Maceió. AGV Logística começa a receber investimentos do fundo norte-americano Equity International. A empresa encerrou o ano com faturamento de $\mathrm{R} \$ 230$ milhões e um crescimento de $130 \%$ com relação ao ano anterior (INTELOG, 2008);

- 2009 - Segundo a Assessoria de Imprensa da empresa, em 2009 ela assume as operações logísticas da filial brasileira do Grupo Pernod Ricard, multinacional francesa co-líder de mercado em bebidas destiladas e vinhos e da $A G C O$, fabricante mundial em equipamentos agrícolas. Além disso, a empresa anunciou o início das operações com três novos clientes: as farmacêuticas Roche e Astra Zeneca e a indústria de confeitos Cadbury Adams Brasil (que detém marcas como Halls, Trident, Bubbaloo e Chiclets). A empresa encerrou o ano com faturamento de $\mathrm{R} \$ 280$ milhões, crescimento de $22 \%$ com relação ao ano anterior(ASSESSORIA DE IMPRENSA - AGV LOGÍSTICA, 2009).

A análise comparativa entre os históricos da empresa nos últimos anos e os resultados obtidos na Tabela 5 mostra que, ao inaugurar seu maior armazém até então, em 2007, a $A G V$ Logística adquire um porte maior que a média do porte dos demais operadores mais eficientes do mercado. Esta operação conduziu a empresa a operar de forma ineficiente em escala se comparada com suas concorrentes. Esta ineficiência relativa foi incrementada no ano seguinte, quando a empresa adquiriu as empresas Delta Serviços Logísticos e E-Service e inaugurou três novas filiais. Mais uma vez a empresa cresceu, em tamanho, em uma proporção maior que a média das empresas mais eficientes do mercado. Essa situação é revertida no ano de 2009, quando sua eficiência atinge o valor de 0.72 . Neste ano a empresa não cresceu fisicamente, mas o mercado continuou sua expansão. Assim, o tamanho da empresa adequou-se naturalmente às novas condições do mercado.

A prestadora de serviços logísticos frigorificados Standard Logística apresentou o desempenho de acordo com a Tabela 6. 
Tabela 6 - Desempenho da empresa Standard Logística para os anos de 2007 a 2010.

\begin{tabular}{cccc}
\hline Ano & Empresa & $\begin{array}{c}\text { Eficiência de } \\
\text { escala }\end{array}$ & $\begin{array}{c}\text { Volume Total de Produtos } \\
\text { Gerenciados - Em Peso } \\
\text { (ton/ano) }\end{array}$ \\
\hline 2007 & Standard Logística & 1,00 & 1.300 .000 \\
2008 & Standard Logística & 1,00 & 1.600 .000 \\
2009 & Standard Logística & 1,00 & 1.920 .000 \\
2010 & Standard Logística & 0,89 & 1.920 .000 \\
\hline
\end{tabular}

A Standard Logística tem como foco oferecer serviços de gerenciamento e execução de toda a cadeia logística frigorificada, desde o armazenamento até a distribuição de produtos. A empresa é a líder na região Sul na área logística para produtos que exigem temperaturas controladas e trabalha com a multimodalidade, ou seja, transporte ferroviário e rodoviário, com uma forte parceria com a empresa América Latina Logística no transporte ferroviário.

Os resultados obtidos através do modelo mostram que, a Standard Logística sempre obteve eficiência relativa máxima, com um volume de produtos gerenciados muito maior que a média de outras empresas do setor. No ano de 2009 , há uma pequena redução na eficiência relativa de escala, apesar do volume manter-se constante, mostrando reações dos concorrentes com relação à produtividade. Através de uma análise cronológica das ações da empresa entre 2006 e 2009, pode-se interpretar sua evolução e relacioná-la aos seus escores de eficiência:

- 2006 - A empresa firma acordo com a McLane do Brasil, unindo a especialidade das duas empresas. A McLane oferece serviços logísticos para produtos secos e multitemperaturas, enquanto a Standard, para frigorificados e climatizados. Com isso, as empresas aumentam seu leque de serviços prestados ao cliente;

- 2007 - Standard Logística inaugura novo armazém com sistema de refrigeração, com capacidade para 15 mil posições-pallet e área total de $105 \mathrm{mil} \mathrm{m}^{2}$. Este investimento aumentou em $40 \%$ a capacidade de área frigorificada do Porto de Santos, o que havia sido realizado pela última vez há dez anos (RIBEIRO, 2007). Para abastecer seus armazéns, a empresa firmou parceria com a América Latina Logística (ALL), que fez, a partir de 2007, o transporte através da sua malha ferroviária norte. Esse investimento visou suprir uma demanda reprimida por serviços ferroviários na região;

- 2008 - A empresa constrói novo terminal para contêineres reefer (contêineres com equipamentos de refrigeração individual). O terminal tem o objetivo de atender à operação de frutas, legumes e verduras da empresa WalMart. A Standard Logística recebe autorização para trabalhar com Recinto Especial para Despacho Aduaneiro de Exportação (Redex), onde os serviços para despachos aduaneiros podem ser realizados no próprio estabelecimento do exportador por funcionários da Receita Federal do Brasil. Isto gerou para empresa um aumento de $400 \%$ na movimentação do terminal de Cubatão, ou seja, de 4 mil a 5 mil toneladas por mês, segundo a Revista Tecnologística (2008);

- 2009 - Segundo a Revista Portuária (2009), a empresa inicia operações no Corredor Intermodal que liga o Centro Oeste ao Porto de Santos, para cargas frigorificadas e secas. $\mathrm{O}$ investimento foi de $\mathrm{R} \$ 15$ milhões para construção de um terminal em Alto Taquari MT, com $35 \mathrm{mil} \mathrm{m}^{2}$. Além disso, nesse ano, a empresa concentra 100\% das operações de armazenagem e ponto de distribuição das marcas da Brasil Foods para o mercado interno do Rio Grande do Sul e investe R\$1 milhão no terminal multimodal de Cruz Alta (ANDRADE, 2009).

Através de comparações entre o histórico da empresa nos últimos anos e os dados da Tabela , observa-se que a Standard Logística é uma outlier no mercado devido ao seu tamanho muito superior à média do tamanho do mercado. Esse padrão é verificado até 2009. Em 2010, a empresa mantém seu volume de produtos gerenciados (em peso) e, pela primeira 
vez, concorrentes se posicionam com escala similar, como pode ser observado na Tabela 6 . Estes fatos conduziram a um decréscimo da eficiência de escala da Standard Logística.

A empresa Martin-Brower apresentou o desempenho de acordo com a Tabela 7.

Tabela 7 - Desempenho da empresa Martin-Bower para os anos de 2007 a 2010.

\begin{tabular}{cccc}
\hline Ano & Empresa & $\begin{array}{c}\text { Eficiência de } \\
\text { escala }\end{array}$ & $\begin{array}{c}\text { Volume Total de Produtos } \\
\text { Gerenciados - Em Peso } \\
\text { (t/ano) }\end{array}$ \\
\hline 2007 & Martin-Brower & 0,90 & 206.000 \\
2008 & Martin-Brower & 1,00 & 252.900 \\
2009 & Martin-Brower & 0,98 & 258.200 \\
2010 & Martin-Brower & 0,76 & 241.300 \\
\hline
\end{tabular}

A empresa Martin-Brower é especializada em food service. É a maior distribuidora logística de produtos para o sistema McDonald's. Nos Estados Unidos, a empresa atende os restaurantes McDonald's desde 1956. Atualmente opera para mais de 6.000 restaurantes e representa $44 \%$ desse mercado. Além disso, a empresa é a operadora logística exclusiva no Brasil, Canadá, América Central e Porto Rico. A Martin-Brower é responsável pela compra, armazenagem, venda e distribuição de produtos secos, resfriados e congelados utilizados pelos clientes.

Os resultados obtidos mostram a empresa Martin-Brower com eficiência de escala média superior à média do mercado. Comparada com as empresas anteriormente descritas, a Martin-Brower possui um volume menor de produtos gerenciados. Além disso, a empresa não teve uma expansão de volume entre todos os anos analisados, apesar da redução de sua eficiência de escala no último ano. Através de uma análise cronológica das ações da empresa pôde-se interpretar sua evolução e os relevantes eventos registrados entre 2005 e 2009:

- 2005 - A empresa garante o fluxo de informações e de produtos como pães, hambúrgueres, alface, queijos, copos, entre os 80 fornecedores credenciados pela McDonald's e os 550 restaurantes da rede no Brasil. A frequência de entrega dos produtos nos restaurantes varia duas a três vezes por semana. A Martin-Brower, no ano de 2005, utilizava-se de uma frota de 84 veículos para distribuição dos produtos pelos restaurantes. O faturamento total da empresa no ano de 2005 foi de $\mathrm{R} \$ 600$ milhões (BORGES, 2005);

- 2006 - A companhia divide um investimento de $\mathrm{R} \$ 10$ milhões com a Bunge Alimentos na joint-venture $M B B$ FoodService, que desenvolve e comercializa amplo portfólio de produtos alimentícios e não alimentícios, armazena e distribui estes produtos para restaurantes comerciais, industriais, hospitalares e cadeias de alimentação. Com isso, a empresa foca em diminuir a parcela proveniente dos negócios com a McDonald's, que chegava a $80 \%$ do faturamento (ARAÚJO, 2006);

- 2007 - A MBB FoodService cresce cerca de $100 \%$ no ano e ainda tem nos seus moldes a parceria entre Martin-Brower e Bunge Alimentos (FELTRIN, 2008);

- 2008 - A Martin-Brower compra a parcela da MBB FoodService da Bunge Alimentos. Assim, a empresa assume $100 \%$ das operações e cresce para o faturamento de cerca de R \$850 milhões, sendo 20\% relativos à MBB FoodService. Assim, há o crescimento em compras e logística fora dos serviços dedicados a rede McDonald's, sendo o objetivo da empresa, diminuir a parcela de representatividade da rede $M c$ Donald's no faturamento de $80 \%$ para $40 \%$. Neste ano, a empresa manteve uma frota de 150 caminhões próprios, com multi-temperaturas e espaço para cargas congeladas, resfriadas e secas. (ELOI, 2008);

- 2009 - Faturamento da empresa passa para R $\$ 930$ milhões, mesmo com a crise de 2009. A empresa, ao final do ano, contava ainda com frota de 176 veículos e expectativa de crescimento de $10 \%$ a $20 \%$ em 2010 (CAZZALI, 2009). 
Comparando-se os dados da tabela, é possível observar que a empresa MartinBrower possuía, supostamente, tamanho adequado do mercado entre os anos de 2007 a 2009, comparáveis as empresas mais eficientes em escala do setor. No último ano, possivelmente impactada pela crise, a empresa Martin-Brower não cresceu nos padrões do seu setor de mercado. Com seu crescimento reduzido e empresas mais eficientes no setor, a MartinBrower teve seus valores de eficiência de escala reduzidos.

\section{CONCLUSÕES}

Este trabalho teve por objetivo avaliar a eficiência de escala de um conjunto de operadores logísticos frigoríficos que atuaram no Brasil no período de 2007 a 2010. Para a avaliação dos escores de eficiência de escala fez-se uso de análise de envelopamento de dados (ou Data Envelopment Analysis - DEA) com inputs e output selecionados por meio de análise estatística multivariada (Análise de Componentes Principais).

Os resultados mostram que o setor apresentou taxa de crescimento elevado e que as empresas acompanharam esta tendência. Retornos decrescentes de escala não foram observados na amostra considerada, o que sugere que o mercado apresentava potenciais de crescimento de escala ainda inexploradas pelos operadores logísticos frigorificados. Ou seja, os resultados sugerem que o setor deve continuar com empresas em processo de fusão ou sendo adquiridas por aquelas que reconheceram a tempo a necessidade de crescer para se aproveitar da onda de crescimento em curso no mercado brasileiro.

O trabalho ainda apresenta análises da evolução dos escores de eficiências com eventos anuais relacionados à alteração do porte de três empresas emblemáticas que operam no setor. Estas análises permitem inferir sobre o potencial da técnica DEA no que toca a políticas de gestão de empresas que tenham necessidade em definir o porte ideal de operação em mercados fortemente mutáveis.

\section{REFERÊNCIAS BIBLIOGRÁFICAS}

[1] ANDRADE, L.H.D. ALL e Standard Logística investem R \$ 1 milhão em terminal de contêineres frigorificados no RS. Portal Transporta Brasil. Disponível em: < http://www.transportabrasil.com.br/2009/08/all-e-standard-logistica-investem-r-1milhao-em-terminal-de-conteineres-frigorificados-no-rs/> . Acesso em: 05/05/2015..

[2] ARAÚJO, P. Martin-Brower amplia suas atividades logísticas no País. Disponível em: <http://www.martin-brower.com.br/imprensa/im_mai06_logistica.html> Acesso em: $17 / 11 / 2011$.

[3] ASSESSORIA DE IMPRENSA - AGV LOGÍSTICA. AGV compra empresas para fazer frente à concorrência. Disponível em: < http://www.agvlogistica.com.br/site/default.asp?TroncoID=726371\&SecaoID=737011 $\&$ SubsecaoID $=0 \&$ Template=../artigosnoticias/user_exibir.asp\&ID=294809> Acesso em: 05/04/2015.

[4] BANKER, R.D., CHARNES, R.F., COOPER, W.W. Some Models for Estimating Technical and Scale Inefficiencies in Data Envelopment Analysis, Management Science, vol.30, p.1078-1092, 1984.

[5] BORGES, C. Martin-Brower abastece restaurantes da rede McDonald's de todo o Brasil. Disponível em: <http://www.martinbrower.com.br/imprensa/im_nov05_mb_abastece_mc.html>. Acesso em: 15/11/2011.

[6] CAMARGO, L.N. de, Fo.; SILVEIRA, V., Jr. Alguns Aspectos no Transporte Refrigerado, Revista Tecnologística, jul. 2010. 
[7] CAZZALI, A.R. Horário e higiene no serviço de fast-food. Disponível em: <http://www.martin-brower.com.br/imprensa/rev_valorsetorial_out09.pdf >. Acesso em: $18 / 11 / 2011$.

[8] CHARNES, A.; COOPER, W.; RHODES, E. Measuring The Efficiency of Decision Making Units, European Journal of Operational Research, n.2, p.429-444, 1978.

[9] COOPER, W.W.; SEIFORD, L.M.; TONE, K. Data Envelopment Analysis, 2. ed., Nova Iorque: Springer, 2007.

[10] ELOI, C. Vendas em alta. Disponível em: $<$ http://www.martinbrower.com.br/imprensa/rev_distribuicao_abr08.pdf>. Acesso em: 18/11/2011.

[11] FELTRIN, A. Martin-Brower chega a R\$ 1 bilhão. Disponível em: <http://www.martinbrower.com.br/imprensa/im_jan08_bilhao.html>. Acesso em: 17/11/2011.

[12] INTELOG - INTELIGÊNCIA EM GESTÃO LOGÍSTICA. Crescimento de 35,7\% em 2005 consolida expansão da AGV Logística. Disponível em: < http://www.newslog.com.br/site/default.asp?TroncoID=907492\&SecaoID=508074\&Su bsecaoID $=715548 \&$ Template $=$. /artigosnoticias/user_exibir.asp $\& I D=625493 \&$ Titulo $=\mathrm{C}$ rescimento $\% 20 \mathrm{de} \% 2035 \% 2 \mathrm{C} 7 \% 25 \% 20 \mathrm{em} \% 202005 \% 20$ consolida $\% 20$ expans $\% \mathrm{E} 3 \mathrm{o} \% 2$ 0da\%20AGV\%20Log\%EDstica> Acesso em: 05/04/2015.

[13] INTELOG - INTELIGÊNCIA EM GESTÃO LOGÍSTICA AGV Logística amplia atuação nacional com inauguração de três filiais. Disponível em:< http://intelog.net/site/default.asp?TroncoID=907492\&SecaoID=508074\&SubsecaoID=8 18291\&Template=../artigosnoticias/user_exibir.asp\&ID=236391\&Titulo=AGV\%20Log $\%$ EDstica\%20amplia\%20atua\%E7\%E3o\%20nacional\%20com\%20inaugura\%E7\%E3o $\% 20 \mathrm{de} \% 20 \operatorname{tr} \%$ EAs\%20filiais > Acesso em: 05/04/2015.

[14] MARINO, S. Área pública de frio cresce no Brasil. Revista Tecnologística, São Paulo, v.176, p.38-39, jul. 2010.

[15] MATTAR, F.N. Pesquisa de marketing: metodologia, planejamento, execução, análise. 2. ed., São Paulo: Atlas, 1994.

[16] RAY, S.C.; CHEN, L. Data Envelopment Analysis for Performance Evaluation: A Childs Guide. University of Connecticut: Department of Economics Working Paper Series, Connecticut, n.38, nov.2009.

[17] REVISTA TECNOLOGÍstiCA. Novo CD da AGV Logística é inaugurado em Vinhedo. São Paulo, v.146, p.6, jan.2008

[18] REVISTA TECNOLOGÍSTICA. Standard Cubatão está apta a operar como Redex. São Paulo, v.152, p.29, jun.2008.

[19] REVISTA TECNOLOGÍSTICA. Mercado Brasileiro de Operadores Logísticos Frigorificados, jul.2007, p.62-72.

[20] REVISTA TECNOLOGÍSTICA. Mercado Brasileiro de Operadores Logísticos Frigorificados, jul.2008, p.80-90.

[21] REVISTA TECNOLOGÍSTICA. Mercado Brasileiro de Operadores Logísticos Frigorificados, jul.2009, p.46-60.

[22] REVISTA TECNOLOGÍSTICA. Mercado Brasileiro de Operadores Logísticos Frigorificados, jul.2010, p.40-50.

[23] RIBEIRO, L. Novo armazém aumenta em $40 \%$ capacidade de armazenagem refrigerada do Porto de Santos. Disponível em: <http:// http:// 
http://www.intelog.net/site/default.asp?TroncoID=907492\&SecaoID=508074\&Subseca oID $=948063 \&$ Template=../artigosnoticias/user_exibir.asp\&ID=819407\&Titulo=Novo \%20armaz\%E9m\%20aumenta\%20em\%2040\%25\%20capacidade\%20de\%20armazenag em\%20refrigerada\%20do\%20Porto\%20de\%20Santos> Acesso em: 05/04/2015.

[24] SINK, H.L.; LANGLEY Jr. C.J. A managerial framework for the acquisition of thirdparty logistics services, Journal of Business Logistics, v.18, p.163-189, 1997.

[25] VIGILÂNCIA SANITÁRIA. Glossário da Vigilância Sanitária. Disponível em: <http://www.saude.ms.gov.br/index.php?templat=vis\&site=116\&id_comp=886\&id_reg $=3482 \&$ voltar=lista\&site_reg=116\&id_comp_orig=886>. Acesso em: 05/04/2015.

[26] ZAMONER, I.P. Avaliação da eficiência relativa de operadores logísticos frigorificados e sua relação com o uso de tecnologias de informação e comunicação, Trabalho de conclusão de curso, Engenharia de Produção, Universidade Federal de Santa Catarina, 2012. 